\title{
Cranial-first approach of laparoscopic left colectomy for T4 descending colon cancer invading the Gerota's fascia
}

\author{
Atsushi Ogura*, Ryutaro Kobayashi, Satoru Kawai, Kenji Takagi, Kiyotaka Kawai, Takashi Maeda, Tsukasa Aritake, \\ Natsuki Nagano and Satoaki Kamiya
}

\begin{abstract}
Background: The safety and feasibility of laparoscopic colectomy for T4 colorectal cancer remain controversial. We believe that setting a "Goal" that will guide the surgeons in returning from the deep layer could be the key to safe en bloc resection of neighboring organs. For descending colon cancer, the cranial-first approach makes it possible to clearly visualize the pancreas and origin of the transverse mesocolon, leading to safe splenic flexure mobilization and complete mesocolic excision, which is the strongest advantage of this approach.

Case presentation: A 75-year-old woman was diagnosed with T4 descending colon cancer invading the Gerota's fascia. We performed laparoscopic left colectomy using the cranial-first approach to set a "Goal" at the inferior border of the pancreas for safe resection of the Gerota's fascia. The total operative time was 233 min, and the estimated blood loss was $98 \mathrm{ml}$. She was discharged after surgery without postoperative complications.

Pathological findings revealed the invasion into the Gerota's fascia, and the resection margin was negative for cancer.

Conclusions: The cranial-first approach of laparoscopic left colectomy appears to be safe and feasible and could be a promising method for selected patients with T4 descending colon cancer invading the Gerota's fascia.
\end{abstract}

Keywords: T4 colon cancer, Cranial-first approach, Left colectomy

\section{Background}

Laparoscopic colectomy for left-sided colon cancer is technically demanding owing to the complicated anatomy around the pancreas and transverse mesocolon [1]. For complete mesocolic excision (CME), dissection of the transverse mesocolon is necessary in the proximity of the pancreas. However, the thick mesocolon often prevents surgeons from detecting the pancreas, resulting in pancreatic injury or incomplete CME.

For left-sided colon cancer, the cranial-first approach is one of the promising procedures for obtaining better surgical outcomes; it has been reported previously [2]. This approach involves dissection of the superior layer of the mesocolon and transverse mesocolon at the

\footnotetext{
* Correspondence: anko0613@hotmail.co.jp

Department of Surgery, Tsushima City Hospital, 3-73, Tachibana Town, Tsushima City, Aichi 496-8537, Japan
}

posterior border of the pancreas cranially; this makes it possible to clearly visualize the pancreas and origin of the transverse mesocolon, leading to safe splenic flexure mobilization and CME, which is the strongest advantage of this approach.

For T4 descending colon cancer invading the Gerota's fascia, dissection of the Gerota's fascia is needed to obtain a sufficient surgical margin. The plane between the Gerota's fascia and left kidney, which leads to the posterior layer of the pancreas, is relatively easy to detect. However, using the medial approach, it is difficult to return from this layer to the superior layer of the mesocolon because the thick Gerota's fascia envelops the pancreas. The cranial-first approach would make it easier to detect the optimal layer in the medial approach, avoiding pancreatic injury and achieving CME. 
Herein, we report the first case of cranial-first approach of laparoscopic left colectomy for T4 descending colon cancer invading the Gerota's fascia.

\section{Case presentation}

Written informed consent was obtained from the patient for publication of this case report, and her anonymity has been protected. A 75-year-old woman presenting with diarrhea was referred to our hospital. Colonoscopy showed a circumferential type II tumor located at the descending colon at the anal side of the splenic flexure. Histopathological examination revealed moderately differentiated adenocarcinoma. Computed tomography (CT) showed a $60 \times 60-\mathrm{mm}$ tumor located at the descending colon, invading the Gerota's fascia (Fig. 1). Some swollen lymph nodes were detected along the left colic artery (LCA) and inferior mesenteric artery (IMA). No distant metastases were seen. Preoperative diagnosis was cT4bN1bM0 stage IIIC locally advanced descending colon cancer. We planned to perform laparoscopic left colectomy with en bloc resection of the Gerota's fascia.

The patient was placed in the lithotomy position under general and epidural anesthesia. The following ports were placed: a 12-mm port at the umbilicus for a scope and 5$\mathrm{mm}$ ports at each quadrant. A fist-size tumor covered with the omentum was detected at the anal side of the splenic flexure. No peritoneal metastasis was observed:

1. Cranial approach to set a "Goal" for the medial approach

First, the omental bursa was opened widely, and the adhesion between the transverse mesocolon and gastric posterior wall was dissected to visualize the pancreatic outline. The superior lobe and the fat of the transverse mesocolon were dissected in the proximity of the pancreas, and the posterior lobe of the transverse mesocolon was exposed cranially
(Fig. 2). The gauze was placed on this layer, which was a "Goal" for the medial approach.

2. Mobilization of the left-sided colon and dissection of the regional nodes

The sigmoid colon was mobilized in a caudal-tocranial direction. After preserving the retroperitoneal tissue, including the hypogastric nerve plexus, ureter, and gonadal vessels, we exposed the root of the IMA clearly and dissected the swollen nodes along the IMA. The LCA was clipped and divided at the origin. Following this, the lateral attachment was dissected, and the descending colon was laterally mobilized to the splenic flexure.

3. Medial approach for safe resection of the Gerota's fascia

For obtaining a sufficient surgical margin, we dissected the Gerota's fascia and exposed the surface of the left kidney just behind the tumor. At the most medial side of the mesocolon behind the IMV, we could easily detect the layer between the posterior lobe of the mesocolon and Gerota's fascia; we cut the posterior lobe above the gauze that was placed as the "Goal" during the cranial approach. Finally, we cut the thick tissue, including the Gerota's fascia and transverse mesocolon, just above the gauze (Fig. 2).

The mobilized left-sided colon was extracted through a trans-umbilical wound and dissected with sufficient proximal and distal margins. Functional end-to-end anastomosis was performed using linear staplers. The total operative time was $233 \mathrm{~min}$, and the estimated total blood loss was $98 \mathrm{ml}$. She was discharged on the 14th day after surgery without postoperative complications.

Pathological findings revealed the invasion into the Gerota's fascia, and the resection margin was negative for cancer (Fig. 3). The number of dissected lymph nodes was 18; however, no metastasis was observed. We

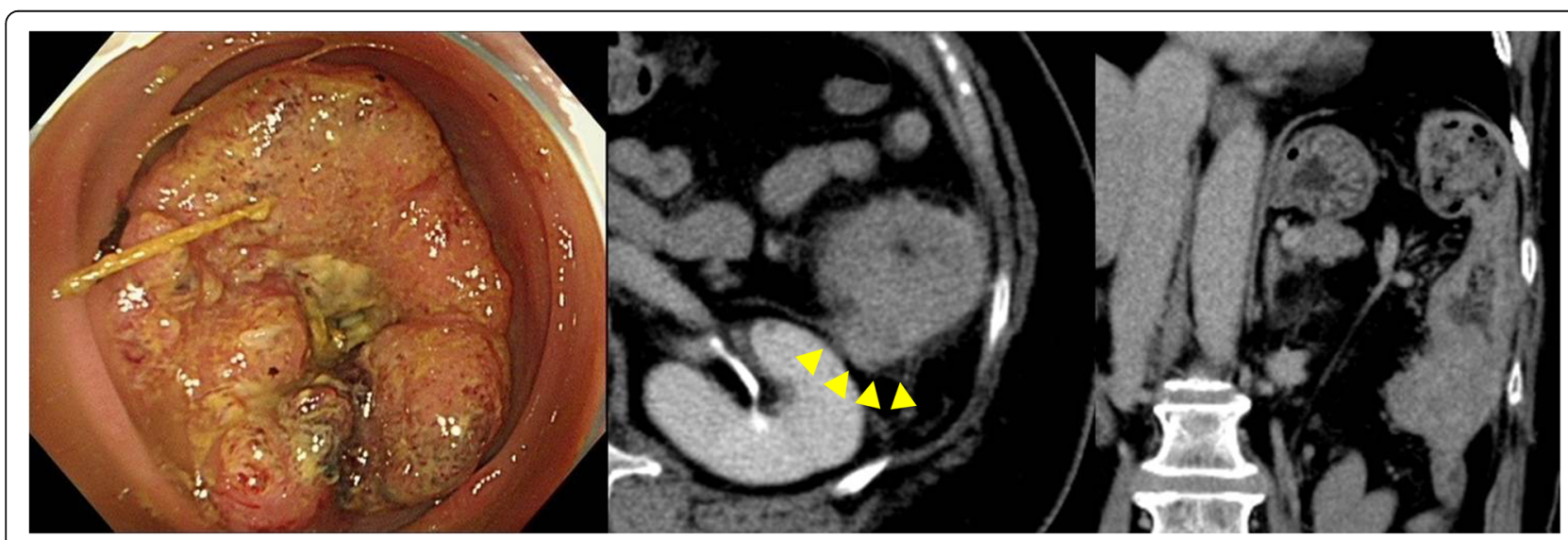

Fig. 1 Colonoscopy and computed tomography: circumferential T4 descending colon cancer invading the Gerota's fascia (arrow head) at the anal side of the splenic flexure 


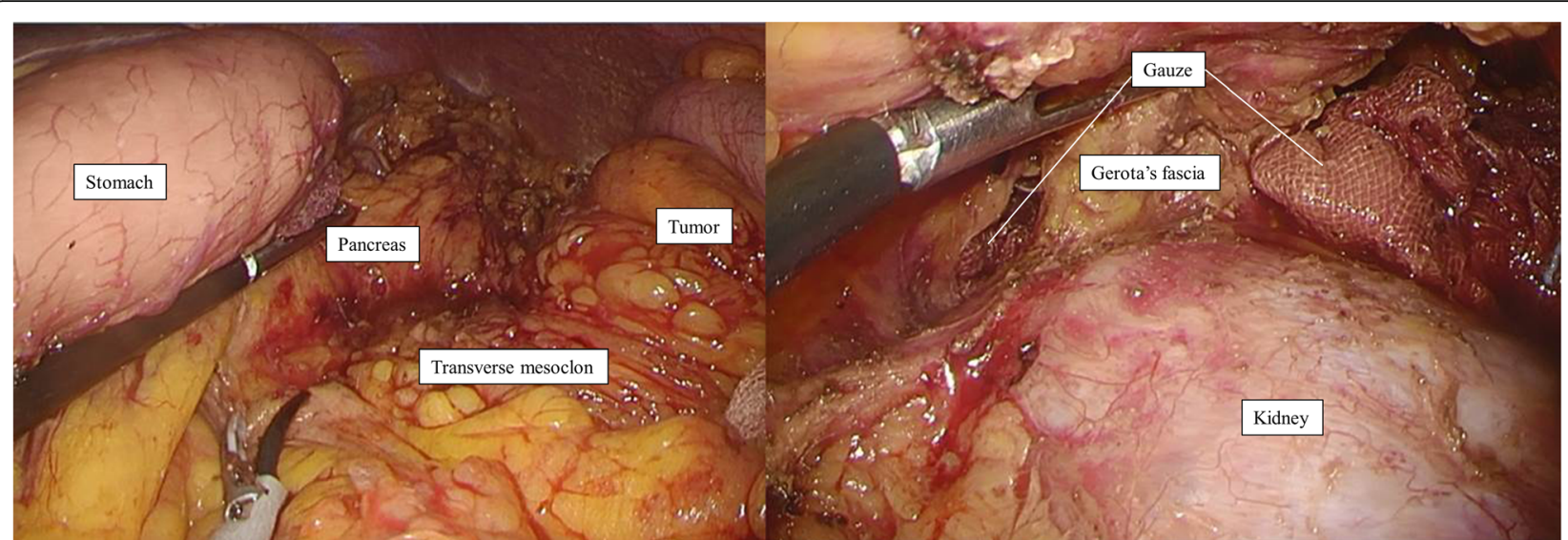

Fig. 2 Laparoscopic cranial view of setting a "Goal" at the inferior border of pancreas and medial view of the resection of the Gerota's fascia

assumed that the preoperative CT finding of lymphadenopathy was due to inflammation induced by the tumor. The pathological diagnosis was pT4bNOM0 pStage IIC.

\section{Discussion}

This is the first case of cranial-first approach of laparoscopic left colectomy for T4 descending colon cancer invading the Gerota's fascia. Previous studies have reported some advantages of laparoscopic surgery: good visualization, less blood loss, and less postoperative pain after colorectal cancer surgery [3-7]. However, the safety and feasibility of laparoscopic surgery for $\mathrm{T} 4$ colorectal cancer remain controversial [3, 8-10]. In terms of extended surgery for $\mathrm{T} 4$ colorectal cancer adhering to or invading neighboring organs, it would be more difficult to return from the deep layer to the shallow layer. Setting a "Goal" using a multidirectional approach of laparoscopic surgery can be the key to safe resection and can help minimize perioperative complications in patients with $\mathrm{T} 4$ colorectal cancer.

For T4 descending colon cancer invading the Gerota's fascia, dissection of the Gerota's fascia behind the tumor is necessary for obtaining sufficient surgical margins. As shown in Fig. 4, the layer between the Gerota's fascia
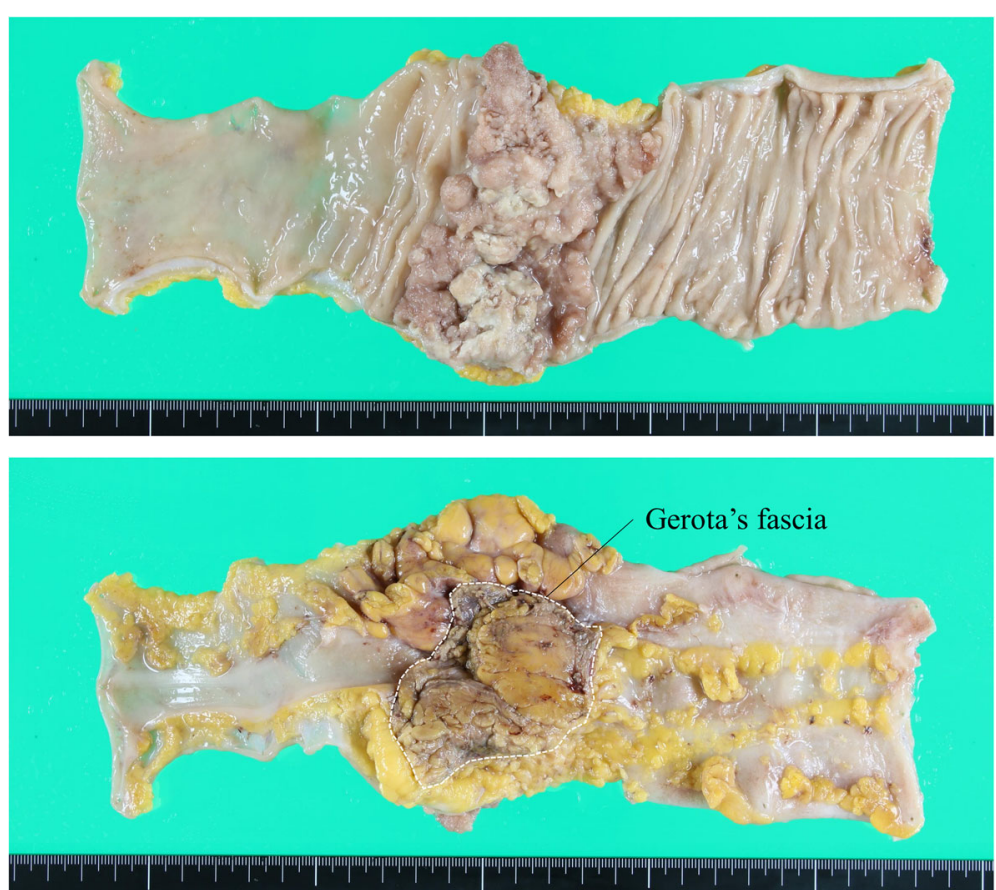

Fig. 3 Resected specimens 


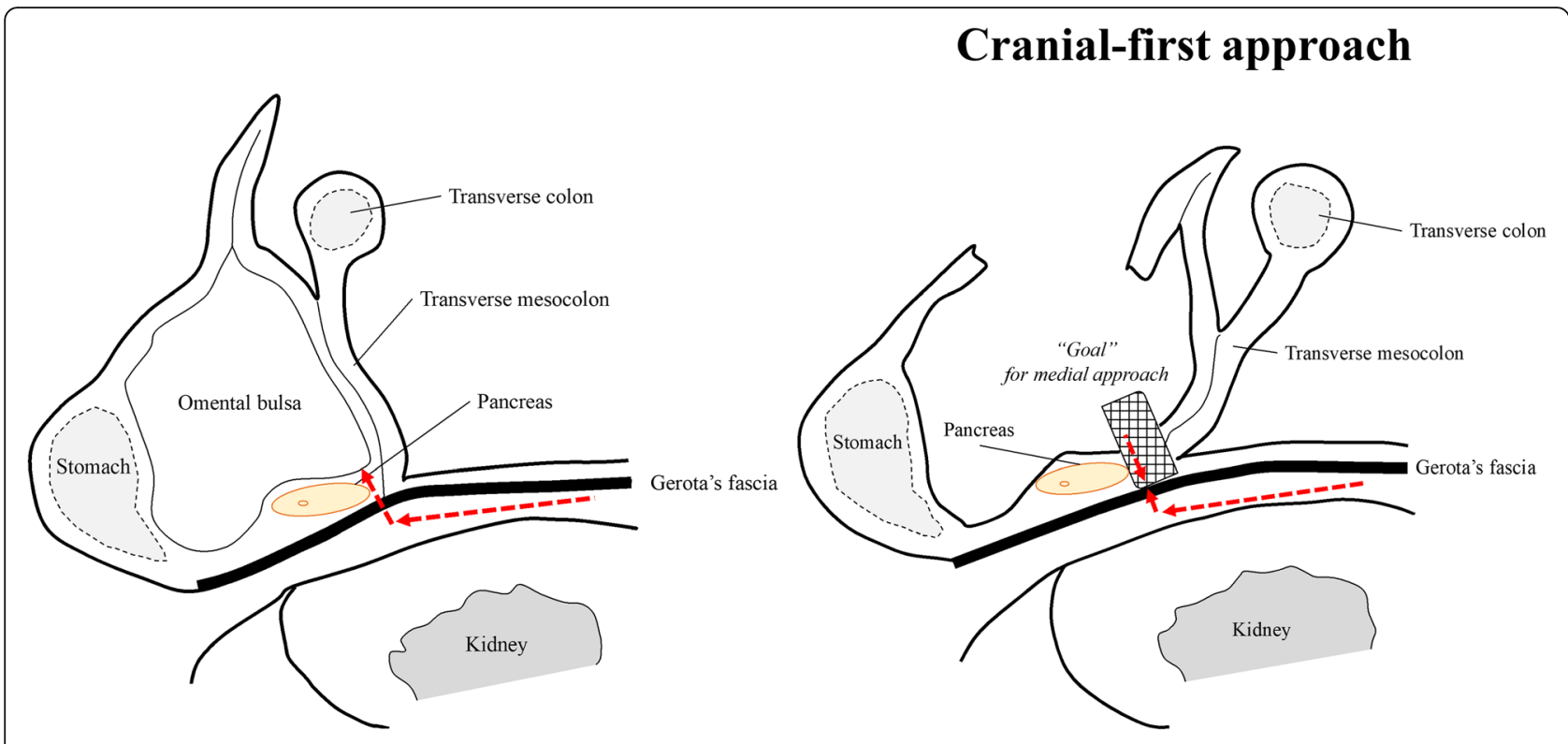

Fig. 4 Scheme of cranial-first approach

and kidney is located below the pancreas. In the final part of the medial approach, the thick Gerota's fascia and mesocolon backed by the pancreas often make dissection difficult due to the risk of pancreatic injury. The cranial-first approach, which we have reported previously, is a promising method for performing safe laparoscopic surgery with splenic flexure mobilization. Using this method of setting a "Goal" for the medial approach, we could easily achieve CME without pancreatic injury (Fig. 4). Owing to the complexity of distinguishing the layer to be dissected, this technique should be performed by laparoscopic surgeons with extensive experience in advanced colorectal cancer surgery.

\section{Conclusions}

The cranial-first approach of laparoscopic left colectomy appears to be safe and feasible and could be a promising method for selected patients with T4 descending colon cancer invading the Gerota's fascia.

\section{Abbreviations}

CME: Complete mesocolic excision; CT: Computed tomography; IMA: Inferior mesenteric artery; LCA: Left colic artery

\section{Acknowledgements}

We thank Toyoharu Yokoi for assisting in the pathological diagnosis of this manuscript.

\section{Authors' contributions}

$\mathrm{AO}$ contributed to the study conception and design. AO and RK contributed to the manuscript writing. All authors were involved in the final approval of the manuscript.

\section{Funding}

This research received no specific grant from any funding agency in the public, commercial, or not-for-profit sectors.
Availability of data and materials

Data sharing is not applicable to this article as no datasets were generated or analyzed during the present study.

\section{Ethics approval and consent to participate}

This study was carried out in accordance with the principles of the Declaration of Helsinki.

\section{Consent for publication}

Written informed consent was obtained from the patient for publication of this case report, and her anonymity has been protected.

\section{Competing interests}

The authors declare that they have no competing interests.

Received: 19 August 2019 Accepted: 27 September 2019

Published online: 28 October 2019

\section{References}

1. Akiyoshi T, Kuroyanagi H, Oya M, Ueno M, Fujimoto Y, Konishi T, et al. Factors affecting difficulty of laparoscopic surgery for left-sided colon cancer. Surg Endosc. 2010;24:2749-54.

2. Ogura A, Kobayashi R, Aritake T, Maeda T, Kawai K, Takagi K, et al. Cranialfirst approach for laparoscopic surgery with splenic flexure mobilization. Tech Coloproctol. 2019;23(7):693-4 Epub ahead of print.

3. Buunen M, Veldkamp R, Hop WC, Kuhry E, Jeekel J, Haglind E, et al. Survival after laparoscopic surgery versus open surgery for colon cancer: long-term outcome of a randomised clinical trial. Lancet Oncol. 2009;10:44-52.

4. Guillou PJ, Quirke P, Thorpe H, Walker J, Jayne DG, Smith AM, et al. Shortterm endpoints of conventional versus laparoscopic-assisted surgery in patients with colorectal cancer (MRC CLASICC trial): multicentre, randomised controlled trial. Lancet. 2005;365:1718-26.

5. Hewett PJ, Allardyce RA, Bagshaw PF, Frampton CM, Frizelle FA, Rieger NA, et al. Short-term outcomes of the Australasian randomized clinical study comparing laparoscopic and conventional open surgical treatments for colon cancer: the ALCCaS trial. Ann Surg. 2008;248:728-38.

6. Kang SB, Park JW, Jeong SY, Nam BH, Choi HS, Kim DW, et al. Open versus laparoscopic surgery for mid or low rectal cancer after neoadjuvant chemoradiotherapy (COREAN trial): short-term outcomes of an open-label randomised controlled trial. Lancet Oncol. 2010;1 1:637-45.

7. Fujii S, Akagi T, Inomata M, Katayama H, Mizusawa J, Ota M, et al. Transitional impact of short- and long-term outcomes of a randomized 
controlled trial to evaluate laparoscopic versus open surgery for colorectal cancer from Japan Clinical Oncology Group Study JCOG0404. Ann Gastroenterol Surg. 2019;3:301-9.

8. Feinberg AE, Chesney TR, Acuna SA, Sammour T, Quereshy FA.

Oncologic outcomes following laparoscopic versus open resection of pT4 colon cancer: a systematic review and meta-analysis. Dis Colon Rectum. 2017;60:116-25.

9. Yamanashi T, Nakamura T, Sato T, Naito M, Miura H, Tsutsui A, et al. Laparoscopic surgery for locally advanced T4 colon cancer: the long-term outcomes and prognostic factors. Surg Today. 2018;48:534-44.

10. Aoki T, Matsuda T, Hasegawa H, Yamashita K, Sumi Y, Ishida R, et al. Outcomes of laparoscopic surgery for pathological T4 colon cancer. Int J Color Dis. 2019;34:1259-65.

\section{Publisher's Note}

Springer Nature remains neutral with regard to jurisdictional claims in published maps and institutional affiliations.

\section{Submit your manuscript to a SpringerOpen ${ }^{\circ}$ journal and benefit from:}

- Convenient online submission

- Rigorous peer review

- Open access: articles freely available online

High visibility within the field

- Retaining the copyright to your article

Submit your next manuscript at $\boldsymbol{\nabla}$ springeropen.com 